\title{
ABO Blood Group Distribution in Serum Hepatitis
}

\author{
R. M. LEWKONIA.* M.B., CH.B.; RONALD FINN, $†$ M.D., M.R.C.P.
}

British Medical fournal, 1969, 3, 268-269

\begin{abstract}
Cummary : A disproportionate excess of blood group 0 $\checkmark$ was found in a circumscribed outbreak of serum hepatitis among patients and staff of a haemodialysis unit. The more severe cases were also mostly of group 0 . This suggests that host factors may be important in the genesis of this disease.
\end{abstract}

\section{Introduction}

Outbreaks of viral hepatitis have occurred in several maintenance haemodialysis units (Drukker et al., 1968). Jones et al. (1967) reported the first year of an outbreak in the Liverpool Unit, and the present report describes the $\mathrm{ABO}$ blood group distribution in this large and continuing epidemic involving 48 known cases over a three-year period. Both serum hepatitis and infectious hepatitis have been incriminated in haemodialysis unit outbreaks (Public Health Laboratory Service Report, 1968), but in the absence of any definitive diagnostic method differentiation between the two conditions can only be based on circumstantial evidence. It was concluded that the circumscribed Liverpool outbreak was due to serum hepatitis (Jones et al., 1967), the principal reasons being (a) the history of direct contact with the blood of a patient undergoing maintenance haemodialysis treatment in almost all cases ; $(b)$ the occurrence of hepatitis in five laboratory technicians who had handled the blood of RDT patients; (c) the absence of secondary spread to contacts of affected cases, with the exception of three relatives who helped with home haemodialysis; and $(d)$ the incubation period was 40 to 150 days. Liability to develop hepatitis in these circumstances was not well correlated with exposure risk as expected, and the observed differential susceptibility was found to be blood-group related.

\section{Methods}

The population studied was divided into cases of hepatitis and subjects at risk who did not develop hepatitis.

Group 1 comprised: (1) 36 cases of clinical icteric hepatitis with confirmatory biochemistry; (2) six cases of anicteric hepatitis with malaise, gastrointestinal symptoms, itching, significantly raised alanine transaminase levels, and recorded serum bilirubin levels within the normal range; and (3) three much transfused haemodialysis patients diagnosed as hepatitis carriers on epidemiological grounds, suggesting transmission to other definite cases. Hepatitis was diagnosed in 10 haemodialysis patients, three other kidney unit patients, three relatives of haemodialysis patients, 22 nurses, five haemodialysis technicians, and five biochemistry technicians. Three of the early cases could not be traced for blood grouping and were excluded from the present series.

Group 2 comprised subjects at risk who showed no manifestations of infection and included: (1) eight haemodialysis patients ; (2) 28 medical and nursing staff who had prolonged contact (over three months) with several haemodialysis patients; (3) one haemodialysis technician; (4) three biochemistry technicians who repeatedly handled the blood of haemodialysis patients; and (5) 11 spouses of haemodialysis patients who, though exposed to only one patient, were considered to be at some risk because three of their number are included in group 1, having been infected in the course of home dialysis.

\footnotetext{
- Senior House Officer, Regional Urological Centre, Sefton General Hospital, Liverpool 15.

+ Consultant Physician, United Liverpool Hospitals ; Research Assistant, Nuffield Unit of Medical Genetics, University of Liverpool.
}

In contrast to the hepatitis cases, delineation of at-risk status is difficult and group 2 is incomplete ; however, it is thought to include not less than three-quarters of those who were at high risk. The classification is nevertheless assumed to be valid because inclusion depended on awareness of risk and availability for grouping, and was not selective with reference to blood group.

Patients, relatives, and staff not previously grouped were ABO-typed with "Eldon cards" to avoid the introduction of potentially infective material to the hospital laboratory.

\section{Results}

The overall series consisted of 96 individuals divided into 45 cases of hepatitis and 51 non-infected at-risk subjects. The $\mathrm{ABO}$ blood group distribution was found to be biased, and Table I shows an excess of group $O$ in the hepatitis cases and a deficit of group $O$ in the at-risk subjects. The difference between the two groups is statistically significant $(P<0 \cdot 01)$. The ABO distribution of the overall sample of 96 individuals was 45 of group O; 38 of group A, 10 of group B, and 3 of group $\mathrm{AB}$, which does not differ greatly from the large Liverpool control series collected by Clarke et al. (1956).

TABLE I

\begin{tabular}{|c|c|c|c|c|c|c|c|c|}
\hline & & & & & & $\mathrm{O}$ & Non-O & Total \\
\hline $\begin{array}{l}\text { Hepatitis } \\
\text { No hepatitis }\end{array}$ & $\because$ & $\because$ & $\because$ & $\begin{array}{l}\cdots \\
\cdots\end{array}$ & $\begin{array}{l}\ldots \\
\cdots\end{array}$ & $\begin{array}{l}29 \\
16 \\
\end{array}$ & $\begin{array}{l}16 \\
35 \\
\end{array}$ & $\begin{array}{l}45 \\
51\end{array}$ \\
\hline Total & .. & .. & .. & $\ldots$ & . & 45 & 51 & 96 \\
\hline
\end{tabular}

Hepatitis cases and at-risk subiects show an excess of group $O$ in the hepatitis cases and a deficit of group $O$ in the at-risk subjects. The 16 non-O cases of hepatitis were combined because of the small numbers; ther

The group $O$ excess was apparent in both the icteric and anicteric hepatitis cases and also when categories of individuals were considered; Table II shows the findings in the 18 patients treated by maintenance haemodialysis during the period of the epidemic.

\begin{tabular}{|c|c|c|c|c|c|c|c|c|}
\hline & & & & & & 0 & Non-O & Total \\
\hline \multirow[t]{2}{*}{$\begin{array}{l}\text { Hepatitis } \\
\text { No hepatitis }\end{array}$} & $\therefore$ & . & $\begin{array}{l}\cdots \\
\cdots\end{array}$ & . & $\begin{array}{l}\cdots \\
\cdots \\
\end{array}$ & $\begin{array}{l}7 \\
1 \\
\end{array}$ & $\begin{array}{l}3 \\
7\end{array}$ & $\begin{array}{r}10 \\
8 \\
\end{array}$ \\
\hline & Total & .. & . & . & . & 8 & 10 & 18 \\
\hline
\end{tabular}
haemodialysis patients who developed hepatitis.

There have been no fatalities in the Liverpool outbreak and most of the cases were comparatively mild, but some severe cases were observed with protracted clinical courses and high serum bilirubin levels (up to $35 \mathrm{mg} . / 100 \mathrm{ml}$.). Clinically, four cases were of outstanding severity and all four individuals were of group $O$. The arithmetic mean of the peak-recorded total serum bilirubin in the icteric cases was $9.6 \mathrm{mg} . / 100 \mathrm{ml}$. in Group $\mathrm{O}$ cases and $6.6 \mathrm{mg} . / 100 \mathrm{ml}$. in non-O cases.

\section{Discussion}

The present data show an increase in group $\mathrm{O}$ among the hepatitis cases and a reciprocal decrease in group $\mathrm{O}$ among those at-risk subjects who did not develop hepatitis. It must be admitted that it is impossible to define the control group 
accurately, but three points should be stressed. All subjects in the control group were in contact with haemodialysis patients for at least three months; exposure varied among the staff, but inclusion of some subjects with a relatively low exposure would only tend to blur the difference between the two groups; and inclusion in the control group was entirely independent of any prior knowledge of the ABO blood group of the subject. Furthermore, the ABO blood group distribution of the Liverpool regular dialysis treatment unit population was similar to the known $\mathrm{ABO}$ blood group frequencies in the Liverpool area. These considerations therefore suggest that subjects of group $\mathrm{O}$ are more likely to develop hepatitis, and the results of similar surveys from other haemodialysis hepatitis outbreaks will therefore be awaited with interest. Until this finding is confirmed in other units the ABO blood group should clearly not be a factor in either patient or staff selection.

$A$ relation between the liability to develop hepatitis and the ABO blood groups would suggest that host factors may be of importance in the genesis of this disease. The high frequency of hepatitis outbreaks in haemodialysis treatment units raises the possibility that the uraemic state may in some way facilitate the spread of this disease, and this again emphasizes the possible importance of host factors in predisposing to hepatitis.

It is of interest that this is not the first report of an altered ABO distribution in hepatitis. Zuckerman and McDonald (1963) found an excess of group A and a corresponding deficiency of group $O$ in 378 cases of "acute hepatitis." Their data were collected from Royal Air Force records, and the type of hepatitis was not specified. If, as seems likely, most of their cases were of infectious hepatitis, then the converse bloodgroup relationship in the present outbreak of serum hepatitis raises the possibility of antigenic differences between the respective viruses. It is, of course, possible that the blood-borne hepatitis associated with maintenance haemodialysis is in some way distinct from the commonly recognized forms.

Associations have been shown between ABO blood groups and several classes of disease, and the significance of these relationships has been discussed by Clarke (1969). Vogel et al. (1960) propounded the thesis that the present-day constitution of the $\mathrm{ABO}$ polymorphism may have been influenced by the great pandemics of the past. Thus differential susceptibility to infectious diseases such as smallpox and plague in individuals of differing blood groups may have conferred selective evolutionary advantages, and thus influenced the present distribution of the $\mathrm{ABO}$ blood groups.

Serum hepatitis may be presumed to be a disease of the era of injections, transfusions, and haemodialysis, though transplacental transmission has also been proposed (Stockes et al., 1954). Infants of mothers suffering from the disease do not usually show clinical signs of jaundice (Sherlock, 1968). An infected abortus or stillborn foetus, however, would not be jaundiced if placental function had been normal, just as jaundice does not occur in $\mathrm{Rh}$-affected foetuses in utero.

Loss of ABO incompatible zygotes (Matsunaga, 1962) would result in a progressive increase in the frequency of $O$ in succeeding generations unless offset by forces hostile to $O$. Differential susceptibility to the effects of serum hepatitis transmitted early in prenatal life might embody a selective anti-O mechanism.

We would like to thank Dr. P. O. Jones and the pathology department of Sefton General Hospital for technical help.

\section{REFERENCES}

Clarke, C. A. (1969). In Selected Topics in Medical Genetics, edited by C. A. Clarke, p. 22. London, Orford University Press.

Clarke, C. A., Edwards, J. W., Haddock, D. R. W., Howel-Evans, A. W., McConnell, R. B., and Sheppard, P. M. (1956). British Medical fournal, 2, 725.

Drukker, W., Schouten, W. A. G., and Alberts, C. (1968). In Dialysis and Renal Transplantation: Proceedings of the 5 th Conference of the European Dialysis and Transplant Association, edited by D. N. S. Kerr, p. 3. Amsterdam, Ereerpta Medica Foundation.

Jones, P. O., Goldsmith, H. J., Wright, F. K., Roberts, C., and Watson, D. C. (1967). Lancet, 1, 835.

Matsunaga, E. (1962). Eugenics Quarterly, 9, 36

Public Health Laboratory Service Report (1968). British Medical Fournal, $3,454$.

Sherlock, S. (1968). Diseases of the Liver and Biliary System, 4th ed. Oxford, Blackwell.

Stockes, J., jun., et al. (1954). Fournal of the American Medical Association, 154, 1059.

Vogel, F., Pettenkofer, H. J., and Helmbold, W. (1960). Acta Genetica et Statistica Medica, 10, 267. Zuckerman, A. J., and McDonald, J. C. (1963). British Medical fournal,
2, 537.

\title{
Bronchial Reactivity to Cigarette and Cigar Smoke
}

\author{
D. G. ROBERTSON, ${ }^{*}$ M.B., M.R.A.C.P. ; D. A. WARRELL, $\dagger$ B.M., M.R.C.P. ; JAN S. NEWTON-HOWES, $\ddagger$ B.SC. \\ C. M. FLETCHER,§ C.B.E., M.D., F.R.C.P.
}

British Medical fournal, 1969, 3, 269-271

$S^{\mathrm{u}}$ ummary: The change in specific airway conductance produced by smoking a cigarette under standard conditions was measured in 91 heavy smokers. Subsequently 19 of the most reactive subjects smoked two cigarettes with different filters and another containing cigar tobacco. The results indicated that reactivity to cigarette smoke was reduced significantly by increasing the retention efficiency of the filter and that reactivity to inhaled cigar-tobacco smoke was no less than that to cigarette smoke.

\section{Introduction}

Many studies have shown that cigarette smokers have a greatly increased morbidity and mortality rate from chronic bronchitis

\footnotetext{
* Research Fellow.

$\dagger$ Medical Registrar
† Scientific Officer.

Seader in Clinical Epidemiology.

Department of Medicine, Royal Postgraduate Medical School, London W.12.
}

and emphysema compared with non-smokers. Pipe and cigar smokers, on the other hand, have rates that are only slightly higher than those of non-smokers. McDermott and Collins (1965) found that men with symptoms of chronic bronchitis had a greater immediate increase of airway resistance on smoking one cigarette than men without such symptoms, suggesting that their increased reactivity might have been related to the development of chronic bronchitis. If this were so, it would be important to know whether smoke from different types of cigarettes or cigars produced different degrees of response. This study was designed to obtain further evidence about the bronchial reactivity to various types of cigarette, a standardized smoking procedure being used.

\section{Methods}

The subjects were male prisoners, all of whom were heavy smokers. Their ages ranged from 19 to 56 years. Those giving a history of asthma were excluded from the study. 